\title{
Analisis Performa Fin Stabilizer untuk menurunkan Rolling pada Perahu menggunakan Software CFD
}

\author{
Mahrita Mufida ${ }^{1)}$, Deri Teguh Santoso ${ }^{2)^{\star}}$, Oleh $^{3)}$ \\ ${ }^{1,2,3)}$ Program Studi Teknik Mesin Universitas Singaperbangsa Karawang \\ JI.H.S Ronggowaluyo, Teluk Jambe Timur, Karawang 41361 \\ Email: mufidamahrita19@gmail.com, deri.teguh@ft.unsika.ac.id, oleh@staff.unsika.ac.id
}

doi: https://doi.org/10.24843/METTEK.2021.v07.i01.p06

\begin{abstract}
Abstrak
Penggunaan perahu sering terjadi banyak insiden kecelakaan yang disebabkan oleh cuaca, ombak yang tinggi, rendahnya tingkat kesadaran keselamatan saat berlayar maupun perahu yang tidak memenuhi standar keselamatan dan teknologi pendukung keselamatan dan kenyamanan yang mengakibatkan perahu terbalik dan karam. Tujuan dari penelitian ini adalah untuk melihat pengaruh performa perahu dengan penambahan variasi fin stabilizer untuk menurunkan gerakan rolling. Metode yang digunakan adalah analisis hambatan dan perilaku gerak kapal menggunakan Software CFD (Computational Fluid Dynamics) untuk melihat pengaruh penambahan fin stabilizer, pengaruh variasi bentuk dan sudut fin stabilizer terhadap gerakan rolling pada perahu. Hasil analisa dengan penambahan fin stabilizer pada perahu dengan menggunakan 2 jenis variasi fin stabilizer yaitu fin stabilizer tipe triangle dengan frekuensi gelombang $0.39 \mathrm{~Hz}$, tinggi gelombang $0.2 \mathrm{~m}$, kecepatan arus $1 \mathrm{~m} / \mathrm{s}$, kecepatan angin 5 knot dan kecepatan 2 knot lebih efektif mereduksi sampai dengan 5\% gaya rolling yang terjadi pada perahu dengan kondisi air laut yang tenang dengan ketinggian gelombang yang tidak terlalu tinggi. Sedangkan hasil analisa dari perahu dengan penambahan fin stabilizer tipe propeller pada perahu dengan frekuensi gelombang $0.76408 \mathrm{~Hz}$, tinggi gelombang $0.4 \mathrm{~m}$, kecepatan arus $2 \mathrm{~m} / \mathrm{s}$, kecepatan angin 15 knot dan kecepatan 4 knot lebih efektif mereduksi sampai $7 \%$ gaya rolling yang terjadi pada perahu dengan kondisi air laut yang sebenarnya.
\end{abstract}

Kata kunci: Perahu, Fin Stabilizer, Gerak Kapal, Hambatan, CFD

\begin{abstract}
The use of boats often occurs with many accidents caused by weather, high waves, low levels of safety awareness while sailing or boats that do not meet safety standards and supporting technology for safety and comfort which results in the boat overturning and sinking. The purpose of this research is to see the effect of boat performance with the addition of variations of the fin stabilizer to reduce rolling motion. The method used is the analysis of the resistance and motion behavior of the ship using CFD Software (Computational Fluid Dynamics) to see the effect of adding a fin stabilizer, the effect of variations in the shape and angle of the fin stabilizer on the rolling motion of the boat. The analysis results with the addition of a fin stabilizer on the boat using 2 types of variations of the fin stabilizer, namely the triangular fin stabilizer with a wave frequency of $0.39 \mathrm{~Hz}$, a wave height of $0.2 \mathrm{~m}$, a current speed of $1 \mathrm{~m} / \mathrm{s}$, a wind speed of 5 knots and a speed of 2 knots more effectively reducing to with 5\% of the rolling force that occurs in boats with calm sea water conditions with not too high wave heights. While the results of the analysis of the boat with the addition of propeller type fin stabilizer on the boat with a wave frequency of $0.76408 \mathrm{~Hz}$, wave height $0.4 \mathrm{~m}$, current speed $2 \mathrm{~m} / \mathrm{s}$, wind speed 15 knots and speed 4 knots more effectively reduce up to $7 \%$ of the rolling force that occurs at boat with real sea water conditions.
\end{abstract}

Keywords: Boat, Fin Stabilizer, Boat Motion, Barriers, CFD

Penulis korespondensi,

Email: deri.teguh@ft.unsika.ac.id 


\section{PENDAHULUAN}

Indonesia adalah negara kepulauan yang memiliki luas perairan $3.257 .483 \mathrm{~km}$ salah satu kesulitan dari negara kepulauan adalah terbatasnya sarana transportasi antar pulau yang sering digunakan adalah sarana transportasi laut[1]. Transportasi air yang digunakan salah satunya perahu yang mempunyai kegunaan untuk memindahkan barang atau orang di laut, danau dan sungai[2]. Penggunaan perahu sering terjadi banyak insiden kecelakaan yang disebabkan oleh cuaca, ombak yang tinggi, rendahnya tingkat kesadaran keselamatan saat berlayar maupun perahu yang tidak memenuhi standar keselamatan dan teknologi pendukung keselamatan dan kenyamanan yang mengakibatkan perahu terbalik dan karam. Seperti terjadinya insiden kapal nelayan KM Puspita Jaya tenggelam pada tanggal 20 Juni 2020 di perairan selat sunda di Kabupaten Pandeglang Banten[4]. Disebabkan hantaman gelombang tinggi yang menyebabkan perahu terbalik dan akhirnya tenggelam. Insiden tersebut perlunya peningkatan lebih dari sistem keamanan untuk perahu terutama dari segi keseimbangan dan daya tahan dari gerakan roll ombak. Salah satu cara untuk menjaga kenyamanan dan keamanan para penumpang adalah dengan memperhatikan sistem stabilitas maupun olah gerak kapal pada saat berlayar mengarungi lautan. Kemampuan olah gerak kapal (seakeeping) merupakan salah satu aspek penting yang berkaitan dengan gerakan kapal dalam merespon pengaruh gaya-gaya luar yang bekerja pada kapal. Dalam meningkatkan upaya kualitas dari olah gerak pada kapal, penggunaan sistem anti-roll pada kapal mampu mempengaruhi respon gerakan rolling pada kapal salah satu sistem anti-roll adalah fin stabilizer[5]. Permasalahan tersebut dapat disikapi oleh peneliti dengan melakukan analisa yang mampu memberikan kestabilan pada perahu menjadi lebih tinggi. Peneliti akan menganalisa performa fin stabilizer untuk menurunkan gerakan rolling pada perahu menggunakan software berbasis computational fluid dynamics yang merupakan pengembangan dari alat gyroscope stabilizer untuk meredam gulungan ombak pada perahu[6]. Penelitian ini dilakukan untuk memprediksi pengaruh fin stabilizer terhadap hambatan perahu, mengetahui seberapa besar pengaruh fin stabilizer terhadap perilaku gerak perahu.

\section{METODE}

\subsection{Diagram Alir Penelitian}

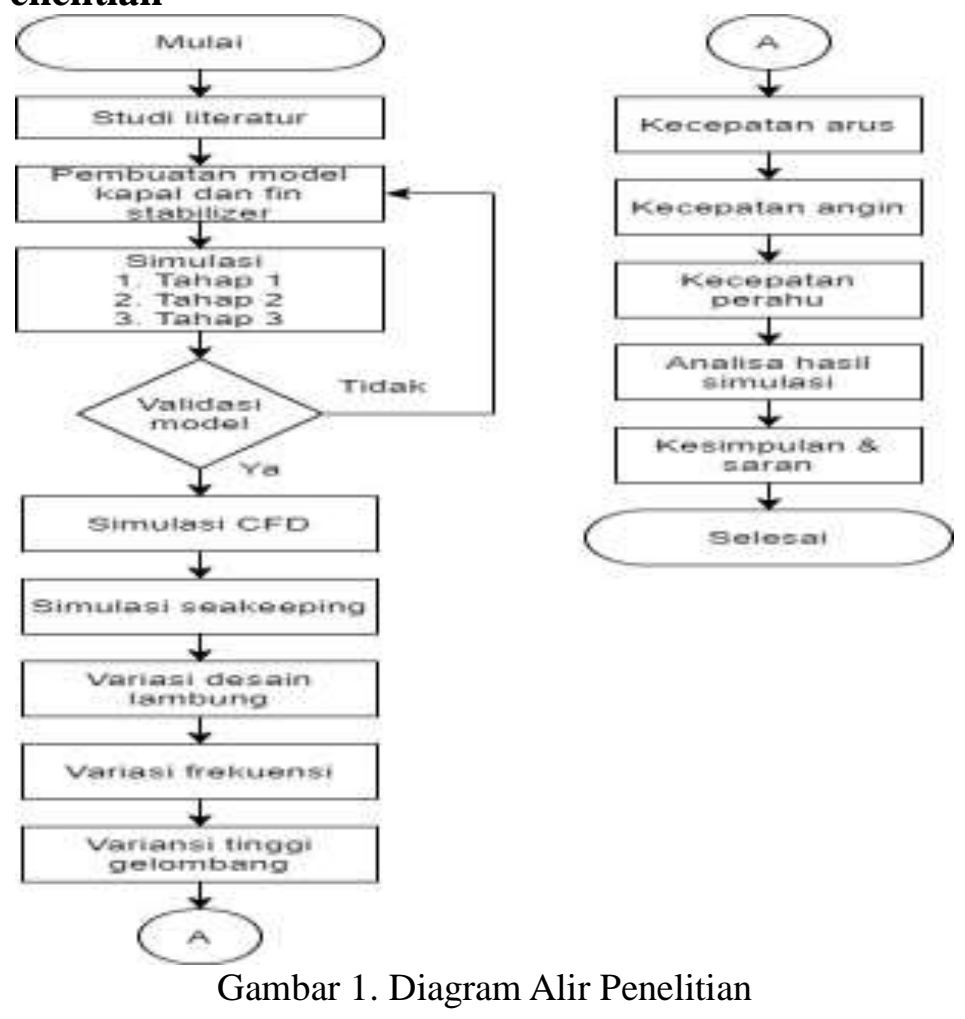




\subsection{Pengumpulan Data}

Penelitian ini menggunakan sampel perahu penelitian sebelumnya dengan penambahan fin stabilizer yang divariasikan pada variabel sudut dan lebar penampang fin stabilizer[6].

- LOA (Length over all) : panjang kapal keseluruhan yang diukur dari ujung buritan sampai ujung haluan.

- $\quad$ LBP (Length between perpensdiculars) : panjang antara kedua garis tegak haluan yang diukur pada garis air laut.

- B (Breadth) lebar yang direncanakan : jarak mendatar dari gading tengah yang diukur pada bagian luar gading (tidak termasuk tebal pelat lambung).

- H (D) Depth (tinggi terendah dari geladak) : jarak tegak dari garis dasar sampai garis geladak yang terendah, umumnya diukur di tengah-tengah panjang kapal.

- $\mathrm{T}$ (Draf) sarat yang direncanakan : jarak tegak dari garis dasar sampai pada garis air muat.

- Vs : Kecepatan operasional perahu

Tabel 1. Data primer perahu

\begin{tabular}{llc}
\hline No. & \multicolumn{1}{c}{ Dimensi } & Skala Penuh \\
\hline 1. & Length Over All (LOA) & $0,90 \mathrm{~m}$ \\
\hline 2. & Length of Perpendicular (LPP) & $0,53 \mathrm{~m}$ \\
\hline 3. & Breadth $(\mathrm{B})$ & $0,35 \mathrm{~m}$ \\
\hline 4. & Draft Maximum $(\mathrm{T} \mathrm{max)}$ & $0,1 \mathrm{~m}$ \\
\hline 5. & Depth $(\mathrm{H})$ & $0,15 \mathrm{~m}$ \\
\hline 6. & Vs & 0 \\
\hline 7. & Displacement & $4,57 \mathrm{~kg}$ \\
\hline 8. & Thickness & $0,5 \mathrm{~cm}$ \\
\hline
\end{tabular}

Tabel 2. Data sekunder fin stabilizer

\begin{tabular}{ccc}
\hline No. & Item & Keterangan \\
\hline 1. & Material Kapal & Fiberglass, Resin \\
\hline 2. & Material Fin Stabilizer & Alluminium Alloy 1060, PVC \\
\hline
\end{tabular}

Tabel 3. Variasi data fin stabilizer

\begin{tabular}{cccc}
\hline No. & Jenis Fin & Panjang Maksimum Fin & Lebar Fin \\
\hline 1. & Tipe Propeller & $0,45 \mathrm{~m}$ & $0,23 \mathrm{~m}$ \\
\hline 2. & Tipe Triangle & $0,30 \mathrm{~m}$ & $0,15 \mathrm{~m}$ \\
\hline
\end{tabular}

\subsection{Pembuatan Model Kapal dan Model Variasi Fin Stabilizer}

Pembuatan model kapal dan fin stabilizer dalam penelitian ini dibantu dengan software Solidwork.

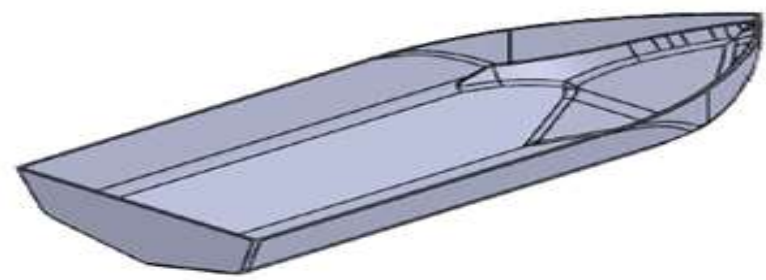

Gambar 2. Desain perahu tanpa fin stabilizer 


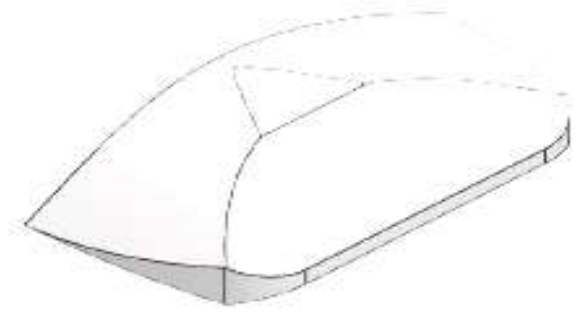

Gambar 3. Desain fin stabilizer tipe propeller

\subsection{Simulasi CFD}

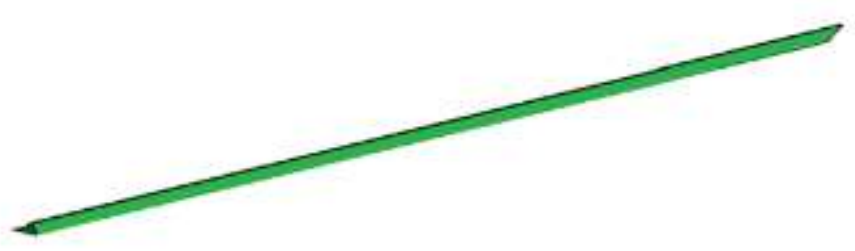

Gambar 4. Desain fin stabilizer tipe triangle

Pada proses simulasi pada Computational Fluid Dynamics terbagi menjadi 3 tahapan besar baik Ansys Aqwa. Berikut merupakan tahapan dalam mensimulasikan CFD :

1. Tahap 1

Pada Ansys Aqwa proses ini berisi mengenai beberapa definisi seperti massa pada kapal, titik berat, radius gyrasi maupun titik bouyancy pada kapal. Selain itu pada proses ini terdapat proses meshing dimana lambung kapal dibagi menjadi banyak elemen-elemen.

2. Tahap 2

Pada Ansys Aqwa maupun Ansys Hydrodinamic Difraction merupakan tahap perhitungan atau tahapan pemecahan masalah berdasar perhitungan numerik yang menjadi dasar perhitungan software.

3. Tahap 3

Pada tahap akhir dilakukan perhitungan analisa dan visualisasi hasil menggunakan program Ansys Hydrodinamic Response. Pada tahap akhir di Ansys Hydrodinamic Response akan menampilkan grafik, data maupun simulasi gerakan kapal sesuai dengan nilai RAO-nya.

\subsection{Validasi Software}

Untuk memberikan hasil yang bisa dipertanggung jawabkan maka analisis dengan software memerlukan tahapan validasi. Ada banyak cara untuk memvalidasi hasil yang diberikan oleh software diantaranya convergence dan grid independence. Penentuan jumlah grid yang dipakai dalam pemodelan kapal berpengaruh terhadap tingkat ketelitian dari model tersebut. Semakin kecil ukuran grid yang digunakan maka akan semakin banyak jumlah grid yang digunakan dan membutuhkan waktu yang lama untuk melakukan simulasi. Pada penelitian ini menggunakan grid 4000 elemen.

\subsection{Simulasi Seakeeping}

Macam Seakeeping antara lain : [6]

1) Surging

Surging adalah gerakan translasi kapal yang terjadi ketika kapal bergerak di sepanjang sumbu $\mathrm{X}$.

2) Swaying

Swaying adalah gerakan translasi kapal yang terjadi ketika kapal bergerak 
Jurnal METTEK Volume 7 No 1 (2021) pp 48 - 56

ojs.unud.ac.id/index.php/mettek

disepanjang sumbu Y.

3) Heaving

Heaving adalah gerakan kapal yang sepanjang sumbu Z

4) Rolling

Rolling adalah kapal yang memutari sumbu X.

5) Pitching

Pitching adalah kapal yang memutari sumbu Y.

6) Yawing

Yawing adalah kapal yang memutari sumbu Z.

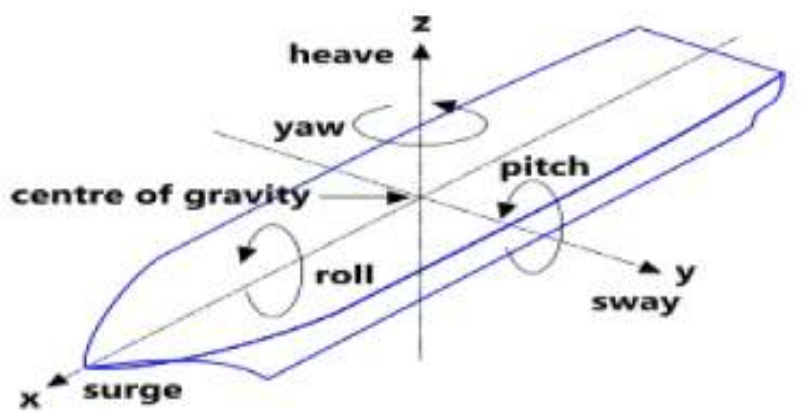

Gambar 5. Gerakan 6 derajat kebebasan kapal [6]

\subsection{Variasi Desain Lambung}

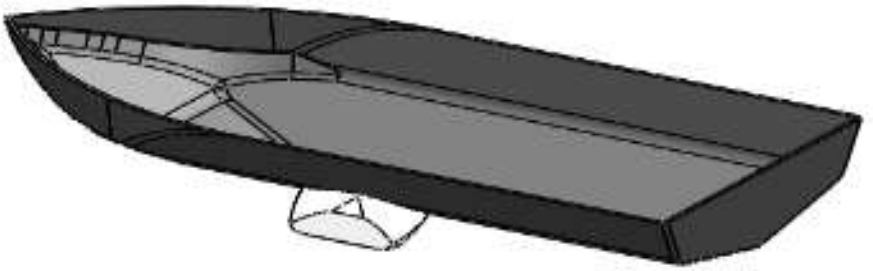

Gambar 6. Desain perahu dengan fin stabilizer tipe propeller

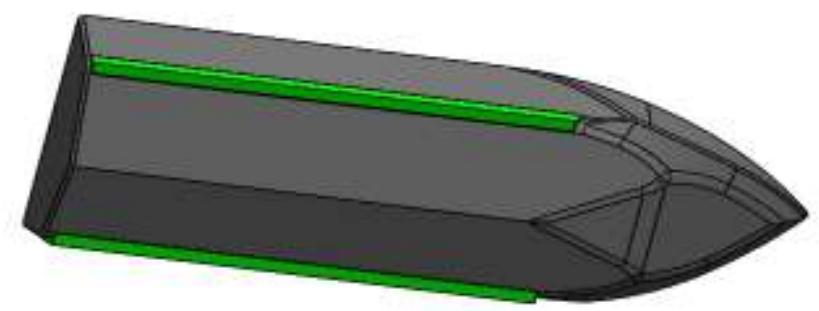

Gambar 7. Desain perahu dengan fin stabilizer tipe triangle

\subsection{Variasi Frekuensi Gelombang}

1) $0.39 \mathrm{~Hz}$

2) $0.57704 \mathrm{~Hz}$

3) $0.76408 \mathrm{~Hz}$

\subsection{Variasi Tinggi Gelombang}
1) $0.2 \mathrm{~m}$
2) $0.3 \mathrm{~m}$
3) $0.33 \mathrm{~m}$ 


\subsection{Variasi Kecepatan Arus Gelombang}
1) $1 \mathrm{~m} / \mathrm{s}$
2) $1.5 \mathrm{~m} / \mathrm{s}$
3) $2 \mathrm{~m} / \mathrm{s}$

2.11. Variasi Kecepatan Angin
1) $5 \mathrm{Knot}$
2) $10 \mathrm{Knot}$
3) $15 \mathrm{Knot}$

\subsection{Variasi Kecepatan Perahu}
1) $2 \mathrm{Knot}$
2) $3 \mathrm{Knot}$
3) $4 \mathrm{Knot}$

\section{HASIL DAN PEMBAHASAN}

\subsection{Analisa Olah Gerak Kapal}

Untuk mengetahui karakteristik gerak suatu kapal, maka akan dipaparkan dalam bentuk karakteristik gerakan-gerakan yang biasa dialami oleh kapal pada saat berlayar. Orientasi sudut datang gelombang dapat dilihat pada gambar dibawah ini.

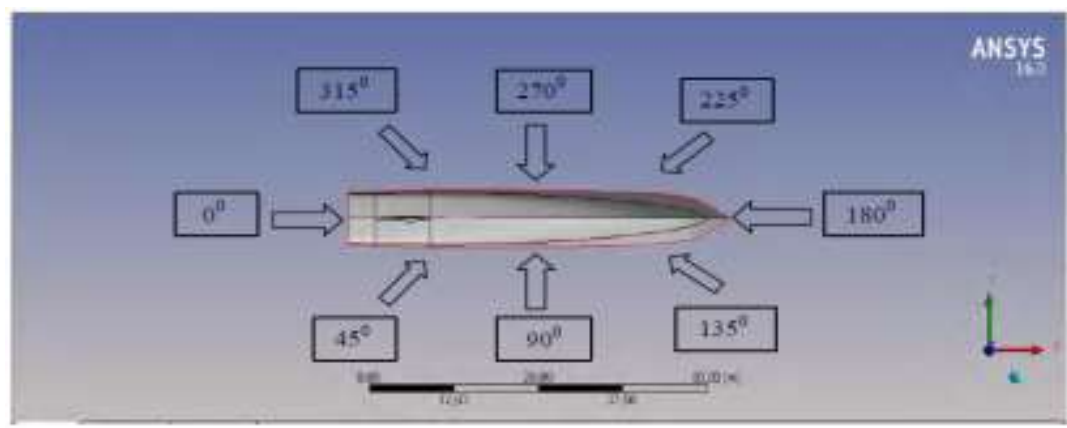

Gambar 8. Orientasi sudut datang gelombang

\subsection{Pemodelan Geometri Kapal}

Pemodelan geometri pada software digunakan untuk mendefinisikan model asli dari objek yang akan diteliti nantinya guna mendapatkan parameter yang sama. Penelitian ini membuat model kapal dan fin stabilizer pada software solidwork yang nantinya akan di konversi ke software Ansys untuk melakukan simulasi CFD dengan cara export file Solidwork menjadi bentuk NURB 3D Surface (.igs). Format igs adalah salah satu format digital pemodelan yang bisa dibaca oleh Ansys Hydrodinamics, maka dari itu hasil output igs dari SolidWork yang akan digunakan sebagai inputan model geometri.

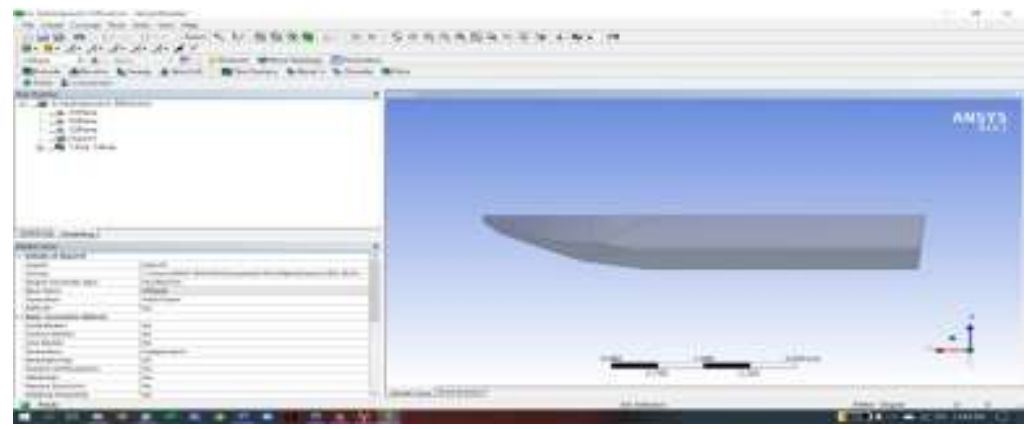

Gambar 9. Hasil konversi geometri kapal dari software Solidwork ke Ansys modeller 


\subsection{Proses Meshing}

Proses meshing bertujuan untuk mendefinisikan kapal menjadi elemen kecil sehingga karakter hidrodinamis dari model bisa didapat. Proses meshing sangat mempengaruhi hasil dari running karena semakin kecil meshing dan semakin banyak jumlah meshing maka akan semakin teliti hasil yang didapat.

\subsection{Simulasi CFD}

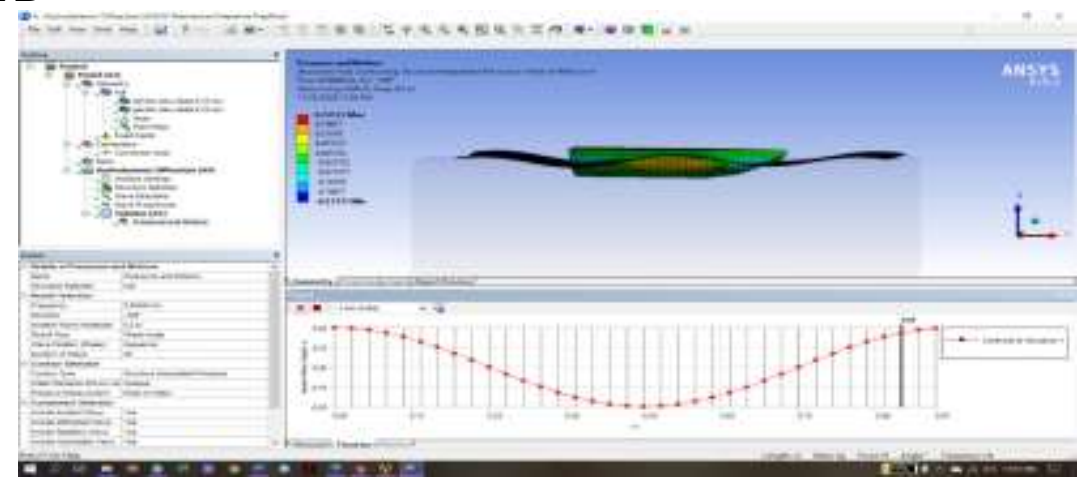

Gambar 10. Simulasi gerak kapal pada Ansys Hydrodynamics

\subsection{Hasil Simulasi CFD}

Tabel 4. Hasil analisis responses amplitudo operator (RAO) dengan berbagai variasi

\begin{tabular}{|c|c|c|c|c|c|c|c|}
\hline \multicolumn{4}{|c|}{ Perahu Tanpa Fin Stabilizer } & \multirow{2}{*}{\multicolumn{2}{|c|}{$\begin{array}{c}\text { Fin Stabilizer Triangle } \\
0.39-0.3-1.5-10-3\end{array}$}} & \multirow{2}{*}{\multicolumn{2}{|c|}{$\begin{array}{c}\text { Fin Stabilizer Propeller } \\
0.39-0.4-2-15-4\end{array}$}} \\
\hline \multirow[b]{2}{*}{ Item } & \multirow{2}{*}{$\begin{array}{l}\text { Wave } \\
\text { Heading }\end{array}$} & \multicolumn{2}{|c|}{$0.39-0.2-1-5-2$} & & & & \\
\hline & & $\begin{array}{c}\text { NILAI RAO } \\
(\mathrm{m} / \mathrm{m})\end{array}$ & KET & $\begin{array}{c}\text { NILAI RAO } \\
(\mathrm{m} / \mathrm{m})\end{array}$ & KET & $\begin{array}{l}\text { NILAI RAO } \\
(\mathrm{m} / \mathrm{m})\end{array}$ & KET \\
\hline \multirow[t]{3}{*}{ Heave } & 0 & 5.566 & Stabil & 7.060 & Stabil & 0.988 & Stabil \\
\hline & 90 & 1.368 & Stabil & 2.155 & Stabil & 3.422 & Tidak Stabil \\
\hline & 180 & 6.598 & Stabil & 1.100 & Stabil & 2.931 & Stabil \\
\hline \multirow[t]{3}{*}{ Pitch } & 0 & 2.058 & Stabil & 3.160 & Stabil & 4.278 & Stabil \\
\hline & 90 & 2.030 & Tidak Stabil & 3.161 & Tidak Stabil & 7.290 & Tidak Stabil \\
\hline & 180 & 4.404 & Stabil & 7.295 & Stabil & 8.642 & Tidak Stabil \\
\hline \multirow[t]{3}{*}{ Roll } & 0 & 1.196 & Tidak Stabil & 8.352 & Tidak Stabil & 4.989 & Tidak Stabil \\
\hline & 90 & 1.450 & Stabil & 3.158 & Stabil & 8.267 & Stabil \\
\hline & 180 & 1.434 & Tidak Stabil & 2.749 & Stabil & 8.117 & Tidak Stabil \\
\hline \multirow[t]{3}{*}{ Surge } & 0 & 3.573 & Stabil & 7.347 & Stabil & 1.370 & Stabil \\
\hline & 90 & 6.368 & Stabil & 7.361 & Tidak Stabil & 8.377 & Tidak Stabil \\
\hline & 180 & 2.199 & Stabil & 2.733 & Stabil & 9.792 & Stabil \\
\hline \multirow[t]{3}{*}{ Sway } & 0 & 0.970 & Tidak Stabil & 5.913 & Tidak Stabil & 1.621 & Tidak Stabil \\
\hline & 90 & 2.732 & Stabil & 4.189 & Stabil & 6.106 & Stabil \\
\hline & 180 & 7.908 & Tidak Stabil & 3.072 & Tidak Stabil & 1.456 & Tidak Stabil \\
\hline \multirow[t]{3}{*}{ Yaw } & 0 & 5.787 & Tidak Stabil & 2.227 & Tidak Stabil & 4.455 & Tidak Stabil \\
\hline & 90 & 3.010 & Stabil & 4.420 & Stabil & 5.968 & Stabil \\
\hline & 180 & 4.219 & Tidak Stabil & 1.898 & Tidak Stabil & 8.165 & Tidak Stabil \\
\hline
\end{tabular}

Keterangan Warna :

Kuning : Pengaruh sudut fin stabilizer terhadap arah datang gelombang dengan dan tanpa fin stabilizer pada perahu 
Merah : Pengaruh penambahan fin stabilizer terhadap gerakan rolling pada perahu dengan variasi bentuk fin stabilizer

Biru : Adanya pengaruh terhadap gerakan rolling dengan penambahan fin stabilizer pada perahu

Tabel diatas menjelaskan tentang hasil analisis simulasi CFD pada perahu dengan atau tanpa menggunakan fin stabilizer dengan berbagai variasi data yaitu frekuensi, tinggi, kecepatan arus, sudut arah datang gelombang dan kecepatan perahu. Hasilnya menunjukkan bahwa nilai gerakan rolling pada perahu jika tidak menggunakan fin stabilizer sebesar 7.808 $\mathrm{m} / \mathrm{m}$ pada sudut 180 derajat jenis sway arah datang gelombang, sedangkan jika perahu dengan penambahan fin stabilizer tipe triangle gerakan rollingnya sebesar $1.100 \mathrm{~m} / \mathrm{m}$ pada sudut 180 derajat jenis heave arah datang gelombang dan tipe propeller sebesar $0.988 \mathrm{~m} / \mathrm{m}$ pada sudut 0 derajat jenis heave arah datang gelombang, bisa dilihat dari hasil ini terdapat perbedaan yang cukup signifikan dan tentunya sangat berpengaruh untuk menurunkan gerakan rolling yang terjadi dan perahu menjadi lebih stabil pada arah datang gelombang jenis heave jika dibandingkan perahu tidak menggunakan fin stabilizer.

\section{SIMPULAN}

Berdasarkan hasil penelitian yang dilakukan dapat disimpulkan bahwa hasil simulasi pengaruh gerakan rolling pada perahu dengan atau tanpa fin stabilizer, dari hasil analisa menunjukkan dengan penambahan fin stabilizer pada perahu dapat menurunkan gerakan rolling yang terjadi dibandingkan perahu tanpa tambahan fin stabilizer.

Hasil simulasi pengaruh bentuk variasi fin stabilizer terhadap frekuensi, tinggi, kecepatan arus, sudut arah datang gelombang dan kecepatan pada perahu, dari hasil analisa dari penambahan fin stabilizer pada perahu dengan menggunakan 2 jenis variasi fin stabilizer yaitu fin stabilizer tipe triangle dan fin stabilizer tipe propeller, hasil didapat bahwa perahu yang menggunakan penambahan fin stabilizer tipe triangle dengan frekuensi gelombang 0.39 $\mathrm{Hz}$, tinggi gelombang $0.2 \mathrm{~m}$, kecepatan arus $1 \mathrm{~m} / \mathrm{s}$, kecepatan angin 5 knot dan kecepatan 2 knot lebih efektif mereduksi sampai dengan 5\% gaya rolling yang terjadi pada perahu dengan kondisi air laut yang tenang dengan ketinggian gelombang yang tidak terlalu tinggi. Hasil analisa dari perahu menggunakan penambahan fin stabilizer tipe propeller pada perahu dengan frekuensi gelombang $0.76408 \mathrm{~Hz}$, tinggi gelombang $0.4 \mathrm{~m}$, kecepatan arus $2 \mathrm{~m} / \mathrm{s}$, kecepatan angin 15 knot dan kecepatan 4 knot lebih efektif mereduksi sampai $7 \%$ gaya rolling yang terjadi pada perahu dengan kondisi air laut yang sebenarnya.

melakukan analisa performa fin stabilizer, kesesuaian antara pengaplikasian di lapangan dan hasil perhitungan, memang harus diteliti lebih lanjut. Perlu dilakukan penelitian lanjutan dengan mengkaji terhadap material yang sesuai untuk fin stabilizer jika digunakan pada perahu.

\section{DAFTAR PUSTAKA}

[1] Saputra, Azhar Aulia, Mardianto, Endi, Adikoro, Ahmad Harits. Sistem Monitoring dan Sistem Penyeimbang Berat Muatan Kapal Ferry sebagai Antisipasi Kecelakaan. Program Kreativitas Mahasiswa-Teknologi.2013

[2] Djaja, Indra Kusna. Teknik Konstruksi Kapal Baja Jilid 1. 2008

[3] Djaja, Indra Kusna. Teknik Konstruksi Kapal Baja Jilid 2. 2008

[4] Palembang.tribunnews.com Insiden kapal nelayan KM Puspita Jaya tenggelam pada tanggal 20 Juni 2020 diperairan selat sunda di Kabupaten Pandeglang Banten (Diakses pada tanggal 30 Juni 2020).

[5] Airlangga Herbowo, dkk. ANALISA FIN STABILIZER TERHADAP ROLLING PADA 
Jurnal METTEK Volume 7 No 1 (2021) pp 48 - 56

ISSN 2502-3829

ojs.unud.ac.id/index.php/mettek

KAPAL FERRY RO-RO 500 GT DENGAN METODE CFD (COMPUTATIONAL FLUID DYNAMIC). Jurnal Teknik Perkapalan. Volume 05, No.1. 2017

[6] Mudzakir, Fahad Fadlillaahi. Tugas Akhir "Perancangan Prototype Gyroscope Stabilizer". 2019 